\title{
Medical management of decompensated heart failure in adult patients: Part 1: Definition and medical management
}

\author{
Mohamed Elmassry MD, Rubayat Rahman MD, Pablo Paz MD, Barbara Mantilla MD, \\ Scott Shurmur MD, Erwin Argueta Sosa MD
}

\begin{abstract}
Acute decompensated heart failure (ADHF) is the leading cause of hospitalization in patients older than 65 years. It continues to increase in prevalence and is associated with significant mortality and morbidity including frequent hospitalizations. The American Heart Association is predicting that more than 8 million Americans will have heart failure by 2030 and that the total direct costs associated with the disease will rise from \$21 billion in 2012 to $\$ 70$ billion in 2030. The definition of ADHF has important limitations, and its management differs significantly from that of chronic heart failure. Although many large, randomized, controlled clinical trials have been conducted in patients with chronic heart failure, it was not until recently that more studies began to address the management of ADHF. The mainstay of ADHF management involves identification of precipitating factors, oxygen supplementation, sodium and fluid restriction, and diuresis. The phenomenon of diuretic resistance is a significant obstacle to relief of congestion and is a field of active investigation. Other important adjuncts to treatment include noninvasive ventilation, inotropes, vasopressors, nitrates, opiates, and vasopressin receptor antagonists. In this review, we will discuss the terminology and classification of ADHF, and review the multiple modalities and strategies available for the management of this disorder.
\end{abstract}

Keywords: heart failure, medical management, complications, devices, palliative care

\section{INTRODUCTION}

\section{DEFINITION OF HEART FAILURE}

Heart failure (HF) is a clinical syndrome that results from any structural or functional impairment of ventricular filling or ejection of blood. ${ }^{1}$ It may be due to dysfunction of either the right ventricle (RV) or left ventricle (LV). There is no widely accepted nomenclature for HF syndromes requiring hospitalization. Patients are described as having "acute HF," "acute HF syndromes," or "acute decompensated HF." While the

Corresponding author: Mohamed Elmassry Contact Information: Mohamed.Elmassry@ttuhsc.edu DOI: 10.12746/swrccc.v8i36.757 third term has gained the widest acceptance, it too has limitations, for it does not make the important distinction between those with a de novo presentation of HF from those with worsening of previously chronic stable HF. In this paper, we will use the term acute decompensated heart failure (ADHF) to describe the clinical syndrome of new or worsening signs and symptoms of HF, often leading to hospitalization or a visit to the emergency department.

\section{Classification of HEART FAILURE}

During an index hospitalization the initial step in evaluating someone presenting with HF symptoms is to identify the subtype. Ejection fraction (EF) determination is considered important in classification of 
patients with HF due to LV dysfunction due to differing patient demographics, comorbid conditions, prognosis, and response to therapies. ${ }^{2}$ Heart failure may be further classified according to EF into HF with reduced ejection fraction (HFrEF) or HF with preserved ejection fraction (HFpEF; LVEF $\geq 50 \%$ ). HFrEF and HFpEF are also recognized as systolic and diastolic heart failure, respectively. Patients with EF between $41-49 \%$ have also been classified as heart failure with borderline EF (HFbEF). There is also a subset of patients with HFpEF or HFbEF who previously had HFrEF. These patients should be considered as having recovery in EF and may be clinically distinct from those with persistently preserved or reduced EF. ${ }^{3}$ Current American College of Cardiology/American Heart Association (ACC/AHA) guidelines define patients who have LVEF $>40 \%$, but who previously had LVEF $\leq 40 \%$, as heart failure with improved ejection fraction (HFiEF).

\section{PreCipitating factors}

During the process of identifying the type of HF the patient presents with, it is also important to identify potential precipitating factors. The Organized Program To Initiate Lifesaving Treatment In Hospitalized Patients With Heart Failure (OPTIMIZE-HF) study identified at least one exacerbating factor in most patients hospitalized with heart failure. Pneumonia/respiratory disease $(15.3 \%)$, ischemia $(14.7 \%)$, arrhythmia $(13.5 \%)$, and uncontrolled hypertension (10.7\%) were identified most frequently. ${ }^{4}$ Nonadherence to medications was identified in $8.9 \%$ and nonadherence to diet in $5.2 \%$ of patients. Other studies have reported similar findings. ${ }^{5-7}$

\section{INITIAL SYMPTOM MANAGEMENT}

To control the presenting symptoms from decompensated heart failure it is important to understand why they develop. The National Heart Foundation of Australia and the Cardiac Society of Australia and New Zealand have published specific recommendations for the medical management of congestive heart failure. ${ }^{8}$ The diagnosis of decompensated HF starts with a focused history and physical examination to identify precipitating factors and rule out other diagnoses. Signs of congestion and hypoperfusion often guide treatment decisions. ${ }^{9,10}$ Congestion results from elevated ventricular filling pressures, which lead to common symptoms and signs, including dyspnea, cough, oxygen desaturation, extremity edema, weight gain, abdominal fullness, nausea, emesis, abdominal pain, and early satiety. Gheorghiade has described acute heart failure syndromes as a continuum that evolves from hemodynamic congestion to clinical congestion. ${ }^{11,12} \mathrm{He}$ notes that most patients who develop acute cardiogenic pulmonary edema have elevated left ventricular end-diastolic pressures, also known as hemodynamic constriction. However, this may not cause changes on chest $\mathrm{x}$-ray or clinical symptoms if it has developed slowly over a prolonged period. Patients then deteriorate if capillary pressures continue to increase, fluid overload develops, or high pressures cause either additional cardiac dysfunction, pulmonary alveolar capillary damage, or neurohormonal activation. Neurohormonal activation is recognized as a contributing factor to the retention of sodium and water. In addition, fluid overload in the lungs in acute HF may not represent additional fluid accumulation but rather redistribution of fluid to the lungs. This happens secondary to decreased venous capacitance resulting in increased preload, and the impaired ventricular emptying secondary to increased arterial vasoconstriction or afterload. ${ }^{13}$ The following discussion will focus on reviewing accepted and studied approaches for the initial medical management of ADHF.

\section{SODIUM AND FLUID RESTRICTION}

The ACC/AHA recommends sodium restriction in patients with acute or chronic HF, although there are insufficient data to support any specific level of sodium intake in patients with symptomatic HF, as noted in the 2013 ACC/AHA and 2012 European Society of Cardiology (ESC) guidelines. Given the available evidence, we suggest sodium restriction (e.g., $<2$ g/d) in patients with symptomatic HF. The ACC/AHA guidelines suggest some degree of fluid ( 1.5 to $2 \mathrm{~L} /$ day) and sodium restriction $(<3 \mathrm{~g} / \mathrm{d})$ in patients with $A D H F{ }^{14}$ Stricter fluid restriction is indicated in patients with severe (serum sodium $<125 \mathrm{meq} / \mathrm{L}$ ) or worsening hyponatremia. Both the ACC/AHA and the ESC accept that there are insufficient data to support any 
specific level of sodium intake in patients with symptomatic HF. ${ }^{14,15}$ Aliti et al. randomly assigned 75 patients with severe systolic dysfunction to a maximum dietary sodium intake of $800 \mathrm{mg} / \mathrm{day}$ and a maximum fluid intake of $800 \mathrm{~mL} /$ day vs a more relaxed sodium intake of 3 to $5 \mathrm{~g}$ and a fluid intake of at least $2.5 \mathrm{~L} /$ day and found no effect on clinical stability or weight loss at three days of hospitalization. ${ }^{16}$ Travers et al. found no difference in time to reach clinical stability in patients treated with fluid restriction compared to those on free fluid intake. ${ }^{17}$ Perceived thirst was significantly worse in the group with stricter sodium and fluid intake in both studies. Although some studies have suggested a possible benefit from a regimen of hypertonic saline plus furosemide in patients with ADHF, this approach is controversial and is of uncertain safety and efficacy.

\section{DIURETICS}

Loop diuretics are the only medications shown to reliably reduce fluid retention in heart failure. ${ }^{18}$ The intravenous route is preferred for diuretic administration in patients with decompensated HF due to more consistent and predictable pharmacokinetics. ${ }^{15,19,20}$ Furosemide, in particular, has limited bioavailability when given orally. A prospective observational study of 1291 patients with ADHF reported improved inhospital mortality with intravenous furosemide started within 1 hour of presentation compared with later treatment (2.3 versus 6.0 percent). ${ }^{21}$ For patients who are naïve to loop diuretic therapy, intravenous diuresis may be started at a low doses (furosemide 20 to $40 \mathrm{mg}$, bumetanide $1 \mathrm{mg}$, torsemide 10 to $20 \mathrm{mg}$ ). Patients on chronic diuretic therapy may be started at a higher dose; a good rule-of-thumb is up to 2.5 times the maintenance total daily oral dose. Depending on the diuretic response, the dose may be doubled every 2-4 hours up to the recommended maximum. ${ }^{22} \mathrm{~A}$ randomized controlled trial with 308 patients with acute decompensated heart failure found no significant differences in reported symptoms or serum creatinine levels when comparing continuous versus bolus administration of furosemide. ${ }^{23}$ However, the study did note non-significant improvement in dyspnea with high dose compared to low dose diuresis. Patients receiving high dose furosemide had more frequent acute kidney injury events; however, there were no differences in clinical outcomes at 60 days between the two dose strategies. ${ }^{24}$

\section{DiURETIC RESISTANCE}

A significant subgroup of heart failure patients has persistent volume overload requiring progressively higher doses of diuretics, a condition called "diuretic resistance." 25 There is significant variation in the degree of diuretic resistance among patients, and characteristics that help predict poor diuretic responses include low diastolic blood pressures, the absence of edema, advanced heart failure, renal impairment, diabetes mellitus, and atherosclerosis. ${ }^{26,27}$

Practical strategies to counter diuretic resistance include intravenous diuretic administration and 'sequential blockade' with the addition of a thiazide or aldosterone antagonist to the loop diuretic. More controversial approaches include increasing the dosage or switching to a continuous infusion of diuretic, hypertonic saline boluses, and co-administration of albumin in hypoalbuminemic patients. ${ }^{23,28-33}$ Dopaminergic agonists, such as fenoldopam, have not been found have not been shown to be effective. Intravenous vasodilators may improve the clinical status in some patients with diuretic resistance. ${ }^{8}$ Nitrates are the most frequently used drug; they cause vasodilation (reduced afterload) and decrease pulmonary congestion by reducing preload if the patient has enough systemic arterial blood pressure to tolerate them. ${ }^{34}$ Cotter et al. showed that high dose nitrates in combination with low dose furosemide was more effective than low dose nitrates in combination with high dose furosemide. ${ }^{35}$

\section{OpIates}

Opiates may be used in ADHF to reduce patient anxiety and decrease the work of breathing. This in turn decreases sympathetic tone, leading to vasodilatation and a fall in cardiac filling pressures. ${ }^{36,37}$ However, evidence of the benefit of morphine therapy in ADHF is limited. The National Institute for Health and Care Excellence ( NICE) study reviewed opiate use in (morphine or diamorphine) in ADHF and found no evidence of benefit and some evidence of harm, 
but the available evidence was considered low quality. ${ }^{38}$ The largest of the studies found that morphine was associated with increased rates of admission to the intensive care unit and mechanical ventilation. ${ }^{39}$ Morphine remained an independent predictor of mortality (OR 4.8, 95\% Cl 4.52-5.18) even after risk adjustment and exclusion of ventilated patients. The 2012 ESC guidelines suggests considering morphine in some patients with acute pulmonary edema with the goal of reducing anxiety and distress associated with dyspnea. ${ }^{14}$ The 2013 ACC/AHA guidelines do not mention morphine therapy as part of the management of ADHF.

\section{VASODILATORS}

The routine use of vasodilators has not been shown to improve outcomes. ${ }^{38}$ The use of vasodilator therapy in patients with ADHF is based largely on underlying hemodynamics and expert opinion, ${ }^{15,19}$ since evidence on efficacy and safety of vasodilatory therapy in this setting is limited. ${ }^{40}$ The A Study Testing the Effectiveness of Nesiritide in Patients With Acute Decompensated Heart Failure (ASCEND-HF) trial found an increase in hypotension and no change in the outcomes of death and 30-day rehospitalization with nesiritide, despite a borderline significant reduction in dyspnea. ${ }^{41}$ The Registrational Study With Omecamtiv Mecarbil/AMG 423 to Treat Chronic Heart Failure With Reduced Ejection Fraction (GALACTIC) trial reported no improvement in a composite outcome of death and 180-day rehospitalization with early use of non-parenteral vasodilators (high-dose sublingual and transdermal nitrates, oral hydralazine, rapid up-titration of angiotensin converting enzyme inhibitor [ACEI], angiotensin II receptor blocker [ARB], or angiotensinreceptor neprilysin inhibitor [ARNI]), compared with usual care (slow up titration of ACEI, ARB, or ARNI). ${ }^{42}$

Nitrates are the most commonly used vasodilators in ADHF. They primarily produce venodilation and help reduce LV preload and pulmonary congestion. At high doses, however, nitrates also cause arteriolar vasodilation and reduce systemic vascular resistance and LV afterload, theoretically increasing stroke volume and cardiac output. Two small randomized trials of limited quality have suggested that treatment regimens for acute HF that include high-dose nitrate therapy for $\mathrm{ADHF}$ and pulmonary edema may reduce the need for mechanical ventilation. ${ }^{35,40}$ It has been proposed that high-dose nitrate therapy may be particularly helpful and well tolerated in patients presenting with hypertensive HF. ${ }^{43}$ The National Institute for Health and Care Excellence (NICE) performed a systematic review comparing intravenous nitroglycerin with placebo in patients with ADHF in the UK, and found no good quality evidence of improvement in dyspnea with nitrates. ${ }^{38}$ Potential adverse effects of nitroglycerin include hypotension and headache. Nitrates can precipitate hemodynamic collapse in settings in which ventricular filling is important, such as right ventricular infarction or aortic stenosis, or if administered concomitant to of PDE-5 inhibitors such as sildenafil.

\section{VASOPRESSIN RECEPTOR ANTAGONISTS}

Vasopressin receptor antagonists have been investigated as an adjunct to diuretics and other standard therapies in patients with ADHF as a means of countering arterial vasoconstriction, hyponatremia, and water retention. However, the long-term safety and benefit of these drugs are unknown. The Efficacy of Vasopressin Antagonism in hEart failuRE: Outcome Study With Tolvaptan (Everest) trial randomized 4133 patients with ADHF to tolvaptan vs placebo, and found no differences between the groups for the composite of cardiovascular death or hospitalization for heart failure as well as the secondary end points of cardiovascular mortality, cardiovascular death or hospitalization, and worsening heart failure. ${ }^{44}$ Tolvaptan significantly improved serum sodium levels in patients with hyponatremia but was associated with increased thirst and dry mouth. The ACC/AHA classify as 'reasonable' the short-term use of vasopressin antagonists in hospitalized patients with volume overload who have persistent severe hyponatremia and are at risk for cognitive symptoms despite water restriction and maximization of guideline-directed medical therapy, although the long-term safety and benefit of this approach are unknown. ${ }^{15}$ The 2012 ESC guidelines suggest consideration of tolvaptan for HF patients with hyponatremia in an ungraded recommendation. ${ }^{14}$ The potential for hepatotoxicity with 
tolvaptan is a significant concern; the United States Food and Drug Administration recommends that tolvaptan use be limited to 30 days and cautions against its use in patients with liver disease.

\section{INOTROPIC AGENTS}

Addition of an inotrope is suggested for patients with ADHF who develop signs of hemodynamic compromise (hypotension, oliguria, confusion). ${ }^{14}$ Both the ACC/AHA and the ESC support the use of these drugs as a temporizing measure in the setting of severe LV systolic dysfunction with diminished peripheral perfusion and end-organ dysfunction until definitive therapy (coronary revascularization, mechanical circulatory support, or heart transplantation) or resolution of the underlying pathology. ${ }^{14,15}$ Continuous intravenous inotrope infusion is reasonable as a "bridging therapy" in advanced heart failure refractory to guideline-directed medical therapy and qualifying for mechanical circulatory support or cardiac transplantation. In addition, inotropic therapy may be utilized for clinical palliation in end-stage heart failure that remains symptomatic despite optimal medical/device therapy. The administration of intravenous inotropes requires continuous telemetry with frequent monitoring of blood pressure..$^{19}$ Inotropes are not indicated for treatment of ADHF in the setting of preserved systolic function.

Inotropic drugs increase myocardial oxygen consumption and may provoke ischemia, particularly in patients with ischemic heart disease, and may precipitate atrial and ventricular tachyarrhythmias, ${ }^{45,46}$ in the absence of systemic hypoperfusion, inotropes may negatively impact outcomes in patients with ADHF.45,47 A systematic review of randomized controlled trials of inotropes found insufficient evidence to convincingly support the efficacy and safety of these agents in ADHF ${ }^{38}$ The Outcomes of a Prospective Trial of Intravenous Milrinone for Exacerbations of Chronic Heart Failure-OPTIME-CHF (OPTIME-CHF) trial studied milrinone and placebo in 949 patients presenting with acute exacerbation of $\mathrm{CHF}^{45}$ Milrinone therapy was associated with significant increases in hypotension and arrhythmias and a nonsignificant increases in mortality during the hospital stay (3.8 versus 2.3 percent) and at 60 days (10.3 versus 8.9 percent).

\section{VASOPRESSORS}

Vasopressor therapy can be considered in patients with ADHF and marked hypotension on inotropic therapy in order to maintain systemic blood pressure and vital end-organ perfusion, although at the cost of increasing afterload and decreasing cardiac output. ${ }^{14} \mathrm{~A}$ systematic review found no evidence to determine the clinical efficacy and safety of vasopressor therapy in $\mathrm{ADHF}^{38}$ vasopressors used in this setting include norepinephrine, high-dose dopamine ( $>5$ micrograms $/ \mathrm{kg} /$ min), vasopressin, and these should be carefully titrated to achieve adequate perfusion of vital organs. Dopamine and norepinephrine have both beta inotropic and vasopressor activity. Phenylephrine should generally be avoided, since this drug increases afterload markedly without a positive inotropic effect.

\section{VENOUS THROMBOEMBOLISM PROPHYLAXIS}

Prophylaxis against venous thromboembolism (deep vein thrombosis and pulmonary embolism) with low-dose unfractionated heparin or low molecular weight heparin, or fondaparinux is indicated in patients admitted with ADHF who are not already anticoagulated and have no contraindication to anticoagulation. In patients admitted with ADHF who have a contraindication to anticoagulation, prophylaxis with a mechanical device (e.g., intermittent pneumatic compression device) is suggested. ${ }^{19}$

\section{NON-INVASIVE VENTILATION}

Established guidelines for treatment of pulmonary edema include non-invasive ventilation (NIV), which has an important effect on gas exchange and patient support but a limited effect on the rate of patient improvement. ${ }^{48}$ After pulmonary edema develops, changes in ventilatory management do little to change these patients' clinical courses. Whether it is basolaterally-directed fluid transfer or apically-applied positive pressure, the pooled alveolar fluid is very difficult to remove secondary to the disruption of alveolarcapillary units and maladaptive changes to the collagen barrier during healing. Pulmonary edema persists well past the acute illness because these membranes need to be repaired and, over time, replaced with 
an physiologically normal functioning barrier, before alveolar fluid clearance mechanisms can be restored.

Non-invasive ventilation improves ventilation by recruiting alveoli and reduces airway resistance by opening airways. Lung inflation can decrease perivascular interstitial hydrostatic pressure. ${ }^{49,50}$ Therefore, positive airway pressure can theoretically redistribute edema fluid from alveoli to the interstitium ${ }^{51}$ where fluid has less of an impact on gas exchange and compliance than alveolar fluid. ${ }^{52,53}$ Respiratory work and respiratory acidosis are reduced by the increased compliance and reduced airway resistance provided by NIV. ${ }^{52}$ However, NIV can have important complications, especially in lungs with a heterogeneous distribution of edema and varying regional lung volumes. Positive-pressure ventilation has been associated with increased permeability of pulmonary capillaries. ${ }^{54}$ Animal studies have found that stress failure of the alveolar membrane can be caused by high lung volumes secondary to over-inflation. ${ }^{55}$ Mechanical ventilation can produce alterations in surfactant, and high tidal volumes may cause atelectasis by increasing surface tension and elastic recoil. ${ }^{56,57}$ Wyszogrodski suggested that overinflation inactivated surfactant rather than depleting it, ${ }^{58}$ since larger tidal volumes cause large aggregates of surfactant to break down into smaller components which have less surface tension lowering activity. ${ }^{59}$

Non-invasive ventilation also has significant hemodynamic effects. Positive airway pressure increases intrathoracic pressure, which impairs right ventricular (RV) filling. ${ }^{60-62}$ It increases pulmonary vascular resistance by compressing intra-alveolar vessels, which increases RV afterload. ${ }^{63}$ Consequently, RV function is impaired with NIV, leading to decreased left ventricular (LV) filling and preload. However, increased intrathoracic pressures decrease LV afterload by creating a positive pressure difference between intrathoracic and extrathoracic circulation. ${ }^{64}$ In a failing heart, which may be sensitive to changes in afterload, positive airway pressure can improve cardiac output by facilitating LV emptying. Consequently, the hemodynamic effect of NIV are uncertain and may be overlooked as long as gas exchange (i.e., $\mathrm{PaO}_{2}$ ) improves.

SeveralRCTs have demonstrated thatNIV improves respiratory rate, oxygenation, and respiratory acidosis in cardiogenic pulmonary edema ${ }^{52,65-73}$ and reduces the rates of endotracheal intubation. ${ }^{52,74} \mathrm{~A}$ large, multicenter RCT failed to demonstrate any improvement in short-term mortality with NIV compared to standard oxygen therapy, ${ }^{73}$ but several systemic reviews and meta-analyses have reported important benefits. ${ }^{75-77} \mathrm{~A}$ meta-analysis of 15 trials concluded that NIV reduced mortality rate by approximately $45 \%,{ }^{75}$ and Vital et al. found that NIV reduced in hospital mortality by $34 \%{ }^{76}$

\section{Conclusions-Part 1}

Acute decompensated heart failure is characterized by the development of acute dyspnea associated with elevated intracardiac filling pressures with or without pulmonary edema. Appropriate management for ADHF requires identification of the precipitating factors. Intravenous loop diuretics are the initial therapy for patients with ADHF and volume overload. It is important for generalists and cardiologists to be familiar with the different strategies available to counter diuretic resistance. Timely use of noninvasive ventilation is an important adjunct to oxygen supplementation and can prevent intubations. Judicious use of vasodilators, opiates, inotropes and vasopressors can help relieve congestion but have not been shown to reliably improve outcomes and are often associated with significant adverse effects. There is a need for a universally accepted terminology for classifying heart failure syndromes to aid further investigation.

Article citation: Elmassry $\mathrm{M}$, Rahman $\mathrm{R}, \mathrm{Paz} \mathrm{P}$, Mantilla B, Scott Shurmur S, Argueta Sosa E. Medical management of decompensated heart failure in adult patients: Part 1: Definition and medical management. The Southwest Respiratory and Critical Care Chronicles 2020;8(36):1-9

From: Department of Internal Medicine, Texas Tech University Health Sciences Center, Lubbock, Texas Submitted: $5 / 23 / 2020$

Accepted: 6/23/2020

Reviewer: Kenneth Nugent MD Conflicts of interest: none

This work is licensed under a Creative Commons Attribution-ShareAlike 4.0 International License. 


\section{REFERENCES}

1. Yancy CW, Jessup M, Bozkurt B, et al. 2013 ACCF/AHA Guideline for the Management of Heart Failure: Executive Summary. Circulation 2013;128:1810-52.

2. Fonarow GC, Stough WG, Abraham WT, et al. Characteristics, Treatments, and Outcomes of Patients With Preserved Systolic Function Hospitalized for Heart Failure. Journal of the American College of Cardiology 2007;50:768-77.

3. Punnoose LR, Givertz MM, Lewis EF, Pratibhu P, Stevenson LW, Desai AS. Heart Failure With Recovered Ejection Fraction: A Distinct Clinical Entity. Journal of Cardiac Failure 2011;17:527-32.

4. Fonarow GC. Factors Identified as Precipitating Hospital Admissions for Heart Failure and Clinical Outcomes Findings From OPTIMIZE-HF. Archives of Internal Medicine 2008; 168:847.

5. Opasich C, Febo O, Riccardi PG, et al. Concomitant Factors of Decompensation in Chronic Heart Failure. The American Journal of Cardiology 1996;78:354-7.

6. Michalsen A, Konig G, Thimme W. Preventable causative factors leading to hospital admission with decompensated heart failure. Heart 1998;80:437-41.

7. Tsuyuki RT, McKelvie RS, Arnold JMO, et al. Acute Precipitants of Congestive Heart Failure Exacerbations. Archives of Internal Medicine 2001;161:2337.

8. Atherton JJ, Sindone A, De Pasquale CG, et al. National Heart Foundation of Australia and Cardiac Society of Australia and New Zealand: Guidelines for the Prevention, Detection, and Management of Heart Failure in Australia 2018. Heart Lung Circ 2018 Oct;27(10):1123-208.

9. Nohria A, Tsang SW, Fang JC, et al. Clinical assessment identifies hemodynamic profiles that predict outcomes in patients admitted with heart failure. Journal of the American College of Cardiology 2003;41:1797-804.

10. Ponikowski P, Voors AA, Anker SD, et al. 2016 ESC Guidelines for the diagnosis and treatment of acute and chronic heart failure: The Task Force for the diagnosis and treatment of acute and chronic heart failure of the European Society of Cardiology (ESC). Developed with the special contribution. European journal of heart failure 2016;18:891-975.

11. Gheorghiade M, Filippatos G, De Luca L, Burnett J. Congestion in acute heart failure syndromes: an essential target of evaluation and treatment. The American journal of medicine 2006;119:S3-S10.

12. Gheorghiade M, Follath F, Ponikowski P, et al. Assessing and grading congestion in acute heart failure: a scientific statement from the acute heart failure committee of the heart failure association of the European Society of Cardiology and endorsed by the European Society of Intensive Care Medicine. European journal of heart failure 2010;12:423-33.

13. Cotter G, Metra M, Milo-Cotter O, Dittrich HC, Gheorghiade $\mathrm{M}$. Fluid overload in acute heart failure-re-distribution and other mechanisms beyond fluid accumulation. European journal of heart failure 2008;10:165-9.

14. McMurray JJ, Adamopoulos S, Anker SD, et al. ESC Guidelines for the diagnosis and treatment of acute and chronic heart failure 2012: The Task Force for the Diagnosis and Treatment of Acute and Chronic Heart Failure 2012 of the European Society of Cardiology. Developed in collaboration with the Heart Failure Association (HFA) of the ESC. Eur Heart J 2012;33:1787-847.

15. Yancy CW, Jessup M, Bozkurt B, et al. 2013 ACCF/AHA guideline for the management of heart failure: a report of the American College of Cardiology Foundation/American Heart Association Task Force on practice guidelines. Circulation 2013;128:e240-327.

16. Aliti GB, Rabelo ER, Clausell N, Rohde LE, Biolo A, Beckda-Silva L. Aggressive fluid and sodium restriction in acute decompensated heart failure: a randomized clinical trial. JAMA internal medicine 2013;173:1058-64.

17. Travers B, O'Loughlin C, Murphy NF, et al. Fluid restriction in the management of decompensated heart failure: no impact on time to clinical stability. J Card Fail 2007;13:128-32.

18. Yancy CW, Jessup M, Bozkurt B, et al. 2013 ACCF/AHA guideline for the management of heart failure: a report of the American College of Cardiology Foundation/American Heart Association Task Force on Practice Guidelines. Journal of the American College of Cardiology 2013;62:e147-239.

19. Lindenfeld J, Albert NM, Boehmer JP, et al. HFSA 2010 Comprehensive Heart Failure Practice Guideline. J Card Fail 2010;16:e1-194.

20. Stampfer M, Epstein SE, Beiser GD, Braunwald E. Hemodynamic effects of diuresis at rest and during intense upright exercise in patients with impaired cardiac function. Circulation 1968;37:900-11.

21. Matsue Y, Damman K, Voors AA, et al. Time-to-Furosemide Treatment and Mortality in Patients Hospitalized With Acute Heart Failure. J Am Coll Cardiol 2017;69:3042-51.

22. Hunt SA, Abraham WT, Chin MH, et al. 2009 focused update incorporated into the ACC/AHA 2005 Guidelines for the Diagnosis and Management of Heart Failure in Adults: a report of the American College of Cardiology Foundation/American Heart Association Task Force on Practice Guidelines: developed in collaboration with the International Society for Heart and Lung Transplantation. Circulation 2009;119:e391-479.

23. Felker GM, Lee KL, Bull DA, et al. Diuretic strategies in patients with acute decompensated heart failure. N Engl J Med 2011;364:797-805. 
24. Felker GM, O'Connor CM, Braunwald E. Loop diuretics in acute decompensated heart failure: necessary? Evil? A necessary evil? Circulation Heart failure 2009;2:56-62.

25. Pappas L, Filippatos G. Pulmonary Congestion in Acute Heart Failure: From Hemodynamics to Lung Injury and Barrier Dysfunction. Revista Española de Cardiología (English Edition) 2011;64:735-8.

26. Valente MAE, Voors AA, Damman K, et al. Diuretic response in acute heart failure: clinical characteristics and prognostic significance. European heart journal 2014;35:1284-93.

27. Voors AA, Davison BA, Teerlink JR, et al. Diuretic response in patients with acute decompensated heart failure: characteristics and clinical outcome-an analysis from RELAX-AHF. European journal of heart failure 2014;16:1230-40.

28. Bowman BN, Nawarskas JJ, Anderson JR. Treating Diuretic Resistance: An Overview. Cardiology in review 2016; 24:256-60.

29. Shah N, Madanieh R, Alkan M, Dogar MU, Kosmas CE, Vittorio TJ. A perspective on diuretic resistance in chronic congestive heart failure 2017.

30. Jentzer JC, DeWald TA, Hernandez AF. Combination of loop diuretics with thiazide-type diuretics in heart failure. Journal of the American College of Cardiology 2010;56:1527-34.

31. Eng M, Bansal S. Use of natriuretic-doses of spironolactone for treatment of loop diuretic resistant acute decompensated heart failure. 2014:e68-9.

32. Kitsios GD, Mascari P, Ettunsi R, Gray AW. Co-administration of furosemide with albumin for overcoming diuretic resistance in patients with hypoalbuminemia: a meta-analysis. Journal of critical care 2014;29:253-9.

33. Liszkowski M, Nohria A. Rubbing salt into wounds: hypertonic saline to assist with volume removal in heart failure. Current heart failure reports 2010;7:134-9.

34. Wakai A, McCabe A, Kidney R, et al. Nitrates for acute heart failure syndromes. The Cochrane database of systematic reviews 2013:CD005151-CD.

35. Cotter G, Metzkor E, Kaluski E, et al. Randomised trial of high-doseisosorbidedinitratepluslow-dosefurosemideversus high-dose furosemide plus low-dose isosorbide dinitrate in severe pulmonary oedema. Lancet (London, England) 1998; 351:389-93.

36. Hsu HO, Hickey RF, Forbes AR. Morphine decreases peripheral vascular resistance and increases capacitance in man. Anesthesiology 1979;50:98-102.

37. Pur-Shahriari AA, Mills RA, Hoppin FG, Jr., Dexter L. Comparison of chronic and acute effects of morphine sulfate on cardiovascular function. Am J Cardiol 1967;20:654-9.

38. National Clinical Guideline C. National Institute for Health and Care Excellence: Clinical Guidelines. Acute Heart Failure: Diagnosing and Managing Acute Heart Failure in Adults. London: National Institute for Health and Care Excellence
(UK) Copyright (C) National Clinical Guideline Centre, 2014; 2014.

39. Peacock WF, Hollander JE, Diercks DB, Lopatin M, Fonarow G, Emerman CL. Morphine and outcomes in acute decompensated heart failure: an ADHERE analysis. Emerg Med J 2008;25:205-9.

40. Sharon A, Shpirer I, Kaluski E, et al. High-dose intravenous isosorbide-dinitrate is safer and better than Bi-PAP ventilation combined with conventional treatment for severe pulmonary edema. J Am Coll Cardiol 2000;36:832-7.

41. O'Connor CM, Starling RC, Hernandez AF, et al. Effect of nesiritide in patients with acute decompensated heart failure. N Engl J Med 2011;365:32-43.

42. Kozhuharov N, Goudev A, Flores D, et al. Effect of a Strategy of Comprehensive Vasodilation vs Usual Care on Mortality and Heart Failure Rehospitalization Among Patients With Acute Heart Failure: The GALACTIC Randomized Clinical Trial. Jama 2019;322:2292-302.

43. Wang K, Samai K. Role of high-dose intravenous nitrates in hypertensive acute heart failure. Am J Emerg Med 2020; 38:132-7.

44. Konstam MA, Gheorghiade M, Burnett JC, et al. Effects of Oral Tolvaptan in Patients Hospitalized for Worsening Heart FailureThe EVEREST Outcome Trial. JAMA 2007; 297:1319-31.

45. Cuffe MS, Califf RM, Adams KF, Jr., et al. Short-term intravenous milrinone for acute exacerbation of chronic heart failure: a randomized controlled trial. Jama 2002;287:1541-7.

46. Burger AJ, Elkayam U, Neibaur MT, et al. Comparison of the occurrence of ventricular arrhythmias in patients with acutely decompensated congestive heart failure receiving dobutamine versus nesiritide therapy. Am J Cardiol 2001;88: 35-9.

47. Abraham WT, Adams KF, Fonarow GC, et al. In-hospital mortality in patients with acute decompensated heart failure requiring intravenous vasoactive medications: an analysis from the Acute Decompensated Heart Failure National Registry (ADHERE). J Am Coll Cardiol 2005;46:57-64.

48. Bourke SC, Piraino T, Pisani L, Brochard L, Elliott MW. Beyond the guidelines for non-invasive ventilation in acute respiratory failure: implications for practice. The Lancet Respiratory Medicine 2018;6:935-47.

49. Hildebrandt J, Beck K, Scherba S, Parker JC, Taylor AE. Pulmonary interstitial and capillary pressures estimated from intra-alveolar fluid pressures. 1979:643-4.

50. Inoue $H$, Inoue $C$, Hildebrandt J. Vascular and airway pressures, and intersititial edema, affect peribronchial fluid pressure. Journal of applied physiology: respiratory, environmental and exercise physiology 1980;48:177-85.

51. Malo J, Ali J, Wood LD. How does positive end-expiratory pressure reduce intrapulmonary shunt in canine pulmonary 
edema? Journal of applied physiology: respiratory, environmental and exercise physiology 1984;57:1002-10.

52. Bersten AD, Holt AW, Vedig AE, Skowronski GA, Baggoley CJ. Treatment of severe cardiogenic pulmonary edema with continuous positive airway pressure delivered by face mask. The New England journal of medicine 1991;325:1825-30.

53. Staub NC, Nagano H, Pearce ML. Pulmonary edema in dogs, especially the sequence of fluid accumulation in lungs. Journal of applied physiology 1967;22:227-40.

54. Dreyfuss D, Basset G, Soler P, Saumon G. Intermittent positive-pressure hyperventilation with high inflation pressures produces pulmonary microvascular injury in rats. The American review of respiratory disease 1985;132:880-4.

55. Fu Z, Costello ML, Tsukimoto $K$, et al. High lung volume increases stress failure in pulmonary capillaries. Journal of applied physiology (Bethesda, Md: 1985) 1992;73:123-33.

56. Faridy EE, Permutt $S$, Riley RL. Effect of ventilation on surface forces in excised dogs' lungs. Journal of applied physiology 1966;21:1453-62.

57. McClenahan JB, Urtnowski A. Effect of ventilation on surfactant, and its turnover rate. Journal of applied physiology 1967;23:215-20.

58. Wyszogrodski I, Kyei-Aboagye K, Taeusch HW, Jr., Avery ME. Surfactant inactivation by hyperventilation: conservation by end-expiratory pressure. Journal of applied physiology 1975;38:461-6.

59. Albert RK. The role of ventilation-induced surfactant dysfunction and atelectasis in causing acute respiratory distress syndrome. American journal of respiratory and critical care medicine 2012;185:702-8.

60. Guyton AC, Lindsey AW, Abernathy B, Richardson $T$. Venous return at various right atrial pressures and the normal venous return curve. The American journal of physiology 1957;189:609-15.

61. Pinsky MR. Determinants of pulmonary arterial flow variation during respiration. Journal of applied physiology: respiratory, environmental and exercise physiology 1984;56:1237-45.

62. Pinsky MR. Instantaneous venous return curves in an intact canine preparation. Journal of applied physiology: respiratory, environmental and exercise physiology 1984;56: 765-71.

63. Luecke T, Pelosi P. Clinical review: Positive end-expiratory pressure and cardiac output. Critical care (London, England) 2005;9:607-21.

64. Klinger JR. Hemodynamics and positive end-expiratory pressure in critically ill patients. Critical care clinics 1996;12: 841-64.

65. Crane SD, Elliott MW, Gilligan P, Richards K, Gray AJ. Randomised controlled comparison of continuous positive airways pressure, bilevel non-invasive ventilation, and standard treatment in emergency department patients with acute cardiogenic pulmonary oedema. Emergency medicine journal: EMJ 2004;21:155-61.

66. Kelly CA, Newby DE, McDonagh TA, et al. Randomised controlled trial of continuous positive airway pressure and standard oxygen therapy in acute pulmonary oedema; effects on plasma brain natriuretic peptide concentrations. European heart journal 2002;23:1379-86.

67. L'Her E, Duquesne F, Girou E, et al. Noninvasive continuous positive airway pressure in elderly cardiogenic pulmonary edema patients. Intensive care medicine 2004;30:882-8.

68. Lin M, Yang YF, Chiang HT, Chang MS, Chiang BN, Cheitlin MD. Reappraisal of continuous positive airway pressure therapy in acute cardiogenic pulmonary edema. Short-term results and long-term follow-up. Chest 1995;107:1379-86.

69. Masip J, Betbese AJ, Paez J, et al. Non-invasive pressure support ventilation versus conventional oxygen therapy in acute cardiogenic pulmonary oedema: a randomised trial. Lancet (London, England) 2000;356:2126-32.

70. Nava S, Carbone G, DiBattista N, et al. Noninvasive ventilation in cardiogenic pulmonary edema: a multicenter randomized trial. American journal of respiratory and critical care medicine 2003;168:1432-7.

71. Park M, Sangean MC, Volpe MdS, et al. Randomized, prospective trial of oxygen, continuous positive airway pressure, and bilevel positive airway pressure by face mask in acute cardiogenic pulmonary edema. Critical care medicine 2004;32: 2407-15.

72. Takeda S, Nejima J, Takano T, et al. Effect of nasal continuous positive airway pressure on pulmonary edema complicating acute myocardial infarction. Japanese circulation journal 1998;62:553-8.

73. Gray A, Goodacre S, Newby DE, Masson M, Sampson F, Nicholl J. Noninvasive ventilation in acute cardiogenic pulmonary edema. The New England journal of medicine 2008; 359:142-51.

74. Masip J, Mebazaa A, Filippatos GS. Noninvasive ventilation in acute cardiogenic pulmonary edema. The New England journal of medicine 2008;359:2068-9; author reply 9.

75. Masip J, Roque M, Sanchez B, Fernandez R, Subirana M, Exposito JA. Noninvasive ventilation in acute cardiogenic pulmonary edema: systematic review and meta-analysis. JAMA 2005;294:3124-30.

76. Vital FMR, Saconato H, Ladeira MT, et al. Non-invasive positive pressure ventilation (CPAP or bilevel NPPV) for cardiogenic pulmonary edema. The Cochrane database of systematic reviews 2008:CD005351-CD.

77. Winck JC, Azevedo LF, Costa-Pereira A, Antonelli M, Wyatt JC. Efficacy and safety of non-invasive ventilation in the treatment of acute cardiogenic pulmonary edema-a systematic review and meta-analysis. Critical care (London, England) 2006;10:R69-R. 